eISSN: 2659-6482

DOI: https://doi.org/10.14201/pmrt.22400

\title{
LA MÚSICA JAZZ EN LA INSTITUCIÓN EDUCATIVA: UN VIAJE DE TRASLACIÓN DE LA PERIFERIA AL CORAZÓN DEL CANON DE LA MÚSICA CULTA EN OCCIDENTE
}

\section{Jazz Music in the Educational Institution: A Journey of Translation from the Periphery to the Heart of the Canon of Cultured Music in the West}

Javier MERCHÁN SÁNCHEZ-JARA

(Universidad de Salamanca)

javiermerchan@usal.es

María NAVARRO CÁCERES

(Universidad de Salamanca)

maria90@usal.es

RESUMEN: El presente artículo pretende constituirse como una aproximación teórica en torno al proceso de inserción y traslación de la música de jazz en el canon de la música culta en Occidente, monopolizado de manera paradigmática por la música clásica europea. Partiendo de un sustrato teórico conformado en relación a la teoría de los polisistemas, postulada por el investigador Israelí Itamar Even-Zohar, se analizan las sinergias, coyunturas y condicionantes que subyacen a un movimiento de traslación que ha propiciado el cambio de consideración de un género musical como el jazz, desde una concepción como música marginal y minoritaria, asociada a un contexto sociocultural concreto, hasta su reconocimiento como una de las expresiones artísticas más vanguardistas, refinadas y valoradas de la cultura occidental.

Palabras clave: Jazz; didáctica de la música; canon musical; teoría de los polisistemas; hibridación musical; sociología. 
JAVIER MERCHÁN SÁNCHEZ-JARA Y MARÍA NAVARRO CÁCERES

LA MÚSICA JAZZ EN LA INSTITUCIÓN EDUCATIVA: UN VIAJE DE TRASLACIÓN DE LA PERIFERIA

AL CORAZÓN DEL CANON DE LA MÚSICA CULTA EN OCCIDENTE

ABSTRACT: This paper aims to conform a theoretical approach around the process of insertion and translation of jazz music into the canon of cultured western music, monopolized in a paradigmatic way by European classical music. Starting from a theoretical substratum formed in relation to polysystem theory, postulated by the Israeli researcher Itamar Even-Zohar, the synergies, conjunctures and conditioning factors underlying a movement of translation that has led to the change of consideration of a musical genre such as jazz, from a conception as marginal and minority music, associated with a specific socio-cultural context, to its recognition as one of the most avant-garde, refined and valued artistic expressions of Western culture are analysed.

Keywords: Jazz; didactics of music, musical canon; Polysystem theory; musical hybridization.

\section{INTRODUCCIÓN}

La teoría de los polisistemas postulada en 1979 por el filólogo, investigador y profesor en la universidad israelí de Tela Aviv, Itamar Even-Zohar (Tel Aviv, 1939), a través de la obra Polysystem Theory (Even-Zohar, 1979), propone la traslación del foco de atención en el análisis literario desde un paradigma centrado en la taxonomía y estudio individualizado de obras, géneros y estilos, o autores, hacia una nueva propuesta consistente en abordar la cuestión de la producción literaria y su desarrollo desde un punto de vista diacrónico y en relación con una perspectiva mucho más amplia: el sistema literario. Desde esta aproximación más integradora, todos los elementos implicados en una misma cultura o tradición literaria forman un sistema de elementos interdependientes, que se relacionan y afectan de manera mutua y multilateral; de igual manera, estos sistemas interactúan con otros sistemas literarios o culturales para conformar el gran ecosistema cultural o literario sobre el cual se asienta el concepto de polisistema.

Este cambio de posicionamiento del foco representa, en definitiva, una traslación de un paradigma basado en la concepción de la lengua y la literatura como sistema cerrado y estático, donde cada elemento cumple una función predefinida e inmutable, a un sistema de sistemas de carácter heterogéneo y estratificado, con una disposición caótica y abierta de los elementos, cuyo posicionamiento tanto en el estrato como en el sistema está sujeto a continuas tensiones e influencias por parte del resto de los elementos del conjunto (tensión intrasistémica), y por la influencia (a un nivel más global) del resto de sistemas que forman el polisistema (tensión intersistémica). 
JAVIER MERCHÁN SÁNCHEZ-JARA Y MARÍA NAVARRO CÁCERES

LA MÚSICA JAZZ EN LA INSTITUCIÓN EDUCATIVA: UN VIAJE DE TRASLACIÓN DE LA PERIFERIA

AL CORAZÓN DEL CANON DE LA MÚSICA CULTA EN OCCIDENTE

Además de las tensiones y las interferencias entre los elementos del sistema, descritas de forma sintética en los párrafos anteriores, entran en juego otra serie de conceptos como todos aquellos relacionados con el concepto canon literario o los de jerarquía sistémica haciendo referencia, precisamente, al lugar que ocupa cada elemento dentro del conjunto. Así, hablamos de formas próximas al centro del sistema, formas canonizadas o high y formas periféricas, no canonizadas o low. Estas consideraciones y referencias conceptuales constituyen, a nivel esquemático, el marco teórico necesario, tanto para valorar y entender la teoría promulgada por el profesor Even-Zohar como para motivar y sustentar buena parte de las reflexiones que se pretenden aportar en el presente trabajo. Debemos, no obstante, introducir en este punto dos puntualizaciones que afectan directamente a uno de los conceptos referidos con anterioridad; el de canon, y de manera extensiva al proceso de canonización. Por un lado, es necesario aclarar que el propio término de canon, en este contexto, puede ser aproximado desde distintos puntos de vista o dimensiones (Citron, 2000); en nuestro caso nos limitamos, sin pretensión de abordar otras consideraciones que puedan desprenderse de otros contextos o perspectivas, a suscribir la conceptualización que el propio Even-Zohar postula en su teoría: «Las normas y las obras que son aceptadas como legitimas por los grupos dominantes dentro de las instituciones literarias» (Even-Zohar, 1990a).

Una vez hecha esta puntualización es necesario manifestar, de igual manera, que la teoría de los polisistemas puede aplicarse de manera indistinta (como la evolución y desarrollo cronológico de la teoría pone de manifiesto) tanto a formas concretas, a nivel estructural o de producción, como a obras o ítems dentro de una categoría, o en relación con distintos paradigmas, géneros o estilos. Es precisamente esta última perspectiva la que más nos interesa en este momento, toda vez que uno de los objetivos primordiales del presente trabajo será observar cómo un género o estilo musical ${ }^{1}$ pasa de ocupar una localización en la periferia del polisistema de las culturas musicales en Occidente a ocupar lugares preferentes dentro del mismo.

Es interesante observar, de la misma forma, cuál es la influencia ejercida por las nuevas formas canonizadas, sobre el resto de elementos del polisistema; o, dicho de otro modo, cómo estas ejercen su canonicidad. Esta cualidad de canonicidad se sustancia, de manera genérica, de dos modos: según la influencia que la entidad canónica ejerce en relación a la producción de nuevas obras o géneros dentro del mismo ámbito; así pues, encontramos obras, autores o géneros que expresan una canonicidad dinámica, desde el momento que su influencia se muestra como activa y directa en la dinámica del sistema (influye en la creación de obras por imitación o contraposición); y elementos del sistema con canonicidad estática, que, aun

1. La diferenciación entre género y estilo incorpora disquisiciones de cierta complejidad que hacen que en este momento escapen del alcance del presente artículo. Por ello advertimos de la utilización indistinta de ambos términos en este contexto. 
JAVIER MERCHÁN SÁNCHEZ-JARA Y MARÍA NAVARRO CÁCERES

LA MÚSICA JAZZ EN LA INSTITUCIÓN EDUCATIVA: UN VIAJE DE TRASLACIÓN DE LA PERIFERIA

AL CORAZÓN DEL CANON DE LA MÚSICA CULTA EN OCCIDENTE

ocupando posiciones prevalentes dentro del mismo, no generan influencia alguna en las obras o géneros creados en espacios concomitantes.

La teoría de los polisistemas contempla, además, aspectos muy relevantes para el estudio del desarrollo cronológico de este tipo de influencias e interacciones en torno al concepto que podíamos denominar ciclos sistémicos, a través de los cuales es posible explicar y comprender cómo muchas formas o géneros transitan en distintas épocas o ciclos históricos desde la periferia al centro y viceversa, y cómo su lugar es ocupado por otras formas pujantes o emergentes, que con el paso del tiempo serán afectadas de igual manera por fenómenos cíclicos de similar naturaleza.

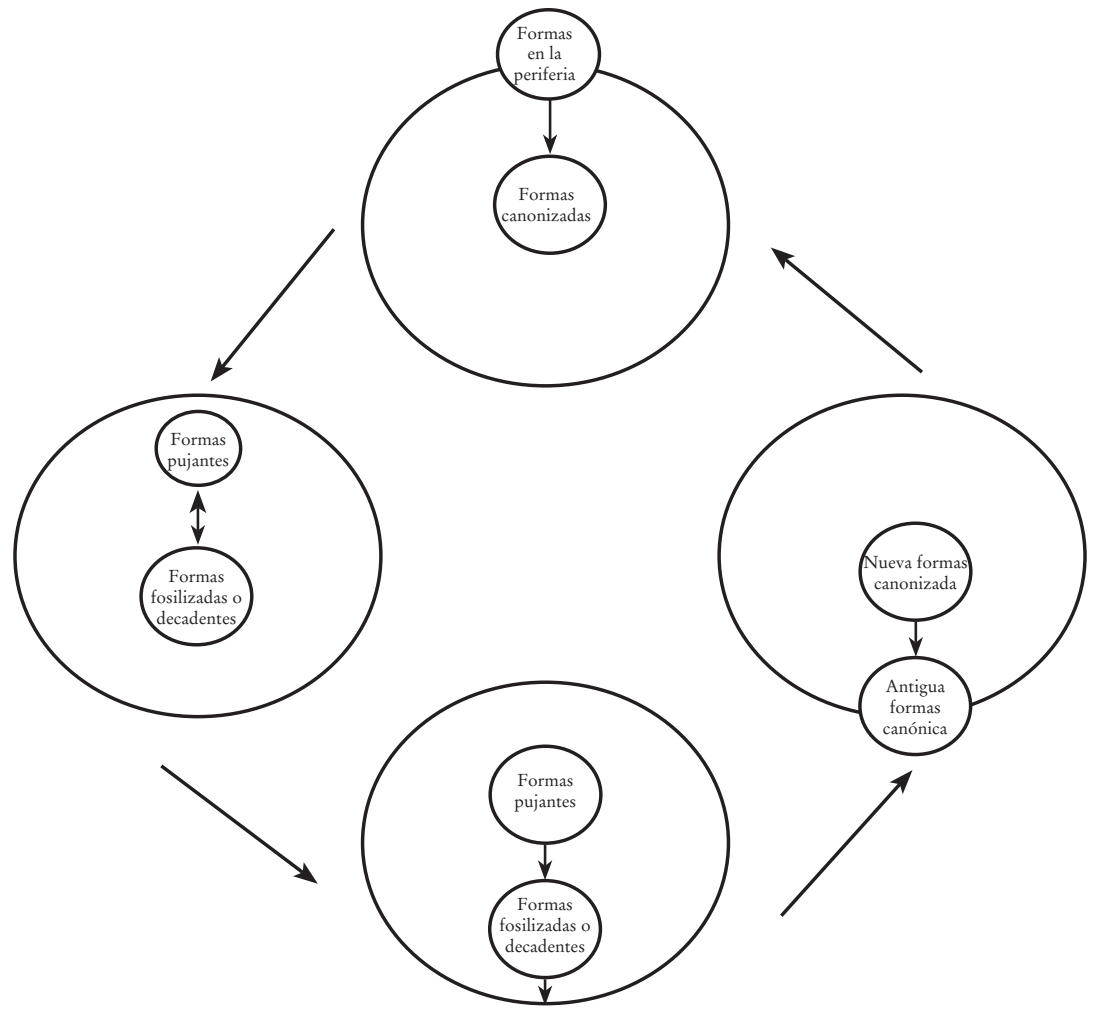

Ilustración 1. Esquema del ciclo sistémico. Fuente: Elaboración propia.

El presente trabajo pretende constituirse como una somera aproximación a una cuestión tan compleja, poliédrica y accesible desde una gran variedad de 
JAVIER MERCHÁN SÁNCHEZ-JARA Y MARÍA NAVARRO CÁCERES

LA MÚSICA JAZZ EN LA INSTITUCIÓN EDUCATIVA: UN VIAJE DE TRASLACIÓN DE LA PERIFERIA

AL CORAZÓN DEL CANON DE LA MÚSICA CULTA EN OCCIDENTE

enfoques distintos, como la inserción de una música originariamente popular (e incluso marginal y estigmatizada) como es la música jazz, hasta colonizar y ocupar un espacio prevalente en el epicentro del polisistema de la denominada música culta occidental.

Al margen de que la mayoría de la literatura científica producida en relación a la teoría del profesor Even-Zohar está vinculada casi de manera exclusiva al ámbito literario, y de que no existen trabajos relevantes que utilicen este marco teórico como sustrato conceptual para el análisis de culturas y sistemas musicales (y menos aún en el caso de la música jazz y del grupo de músicas con la improvisación como elemento fundamental en su desarrollo discursivo), la intención y la perspectiva de la que queremos dotar este texto es la de un análisis que relacione un hecho palpable e incontestable, como es la inserción de la música jazz en el centro de un paradigma cultural monopolizado históricamente de manera insoslayable por la música clásica occidental, desde el conjunto de experiencias de hibridación acontecidas en las últimas décadas, teniendo en todo momento presentes como marco teórico tanto los postulados del profesor Even-Zohar como las posteriores reflexiones y exégesis que sobre el mismo se han desarrollado desde su publicación.

Como objetivos prioritarios planteamos, por un lado, la necesidad de reseñar brevemente las características de este estilo de música, así como sus rasgos constitutivos más esenciales desde el prisma de su origen eminentemente popular y transcultural; $y$, por otro, los motivos, mecanismos y coyunturas que han impulsado esta expresión musical al centro del polisistema, así como las implicaciones, derivaciones e interferencias que este hecho ha provocado en el mismo.

\section{JAZZ, UN EJEMPLO PARADIGMÁTICO DE EXPRESIÓN MUSICAL DE CARÁCTER TRANSCULTURAL}

La música jazz se erige, al margen de cualquier otro tipo de consideraciones de tipo subjetivo, como uno de los emblemas más identificativos de la cultura propia de la sociedad afroamericana (Levine, 1989). Parte de esta asociación, tan fuertemente impregnada en el subconsciente colectivo, deviene del hecho de que esta música ha sido un elemento sobresaliente y omnipresente en el ciclo vital de los integrantes de esta comunidad durante largos periodos de tiempo. Independientemente de esta asociación que se da como válida y verdadera en la mayoría de las personas con un conocimiento mínimo de esta forma de expresión artística, han sido recurrentes las discusiones o debates en torno a la pertenencia de este género musical a nivel identitario entre los distintos grupos sociales que conviven en el país norteamericano. Al igual que ocurre con géneros más cercanos a nuestra cultura, como el flamenco, son muchas voces las que preconizan el concepto jazz como género musical cuyas únicas expresiones válidas y auténticas son producidas 
JAVIER MERCHÁN SÁNCHEZ-JARA Y MARÍA NAVARRO CÁCERES

LA MÚSICA JAZZ EN LA INSTITUCIÓN EDUCATIVA: UN VIAJE DE TRASLACIÓN DE LA PERIFERIA

AL CORAZÓN DEL CANON DE LA MÚSICA CULTA EN OCCIDENTE

por integrantes del colectivo afroamericano, sin considerar la posibilidad de poder participar a artistas ajenos a la misma, sin contravenir los elementos más esenciales y vertebradores de esta expresión musical. Esta consideración que a día de hoy puede resultar inverosímil, descabellada, y hasta incomoda, fue mantenida y defendida con gran vehemencia durante largos periodos de tiempo, incluso por personas fuera del ámbito de la comunidad afroamericana (Gunderson, 2003). ¿Por qué?; quizás la razón más comúnmente asimilada en el seno de esta comunidad, la que motiva con mayor legitimidad la apropiación de este género musical, la encontramos en el hecho de que es precisamente el movimiento diaspórico desde África a Estados Unidos el que propicia el surgimiento de la música jazz (Porter, 2002). Además, la posterior marginación por una parte importante de la cultura mainstream norteamericana hacia la propia comunidad afroamericana en la que se desarrollan el blues ${ }^{2}$ y el jazz constituye un hecho único, propio y diferenciador de esta realidad social en concreto que, en definitiva, propone los elementos necesarios y en el contexto más propicio para la génesis de una manifestación cultural que solo desde su vivencia más cercana e intensa puede asimilarse y/o reproducirse.

Estas argumentaciones han sido esgrimidas desde casi los orígenes del jazz, hasta prácticamente nuestros días, como el hecho que motiva cierta legitimidad dentro de la comunidad afroamericana para erigirse como los destinatarios de este género musical. De igual forma se ha constatado como, al contrario, otros estilos paradigmáticos de la música americana exportados con posterioridad al resto del mundo, como el teatro musical (los conocidos como musicales), que surge de la simbiosis entre el teatro de variedades americano y los minstrel procedentes de la opereta europea, surgen, se desarrollan y se reproducen de igual manera a través de todos los grupos étnicos o socioeconómicos del país (Stempel, 2010). No sucedió lo mismo en ninguna de las primeras etapas de desarrollo y constitución del jazz como género autónomo y consolidado a nivel formal y estilístico, y únicamente en etapas posteriores su penetración en el resto de colectivos socioculturales fue plena y efectiva (Monson, 1995). En este sentido el origen y desarrollo del género jazz en sus primeras etapas, y más concretamente de la manifestación conocida como tradición, está indisolublemente asociado de manera casi exclusiva con una comunidad concreta como la afroamericana, de carácter eminentemente gremial.

Este hecho es especialmente relevante, porque sostiene una de las corrientes teóricas más compartidas en relación a la esencia y a los aspectos más nucleares a nivel constitutivos de este tipo de cultura; una aproximación esencialmente canónica, que postula el jazz como expresión representativa de una determinada

2. Este es quizás el elemento clave para conformar lo que el profesor Even-Zohar denomina el repertorio, es decir, las herramientas y materiales para la producción del producto paradigmático de un sistema polisistema. En este sentido la raíz africana aporta al jazz tanto los esquemas rítmicos (desplazamiento y swing) como el estilo improvisado. 
JAVIER MERCHÁN SÁNCHEZ-JARA Y MARÍA NAVARRO CÁCERES

LA MÚSICA JAZZ EN LA INSTITUCIÓN EDUCATIVA: UN VIAJE DE TRASLACIÓN DE LA PERIFERIA

AL CORAZÓN DEL CANON DE LA MÚSICA CULTA EN OCCIDENTE

comunidad concreta (la afroamericana), en relación con unos cánones estéticos propios y claramente definidos y que además se erige como la cultura legitimadora de una comunidad que defiende su preservación dentro de un paradigma cultural concreto. Por otro lado, y en contraposición a esta perspectiva de carácter taxativo, podemos pergeñar otro tipo de acercamiento más laxo basado en la concepción del jazz como proceso, que contempla su esencia más definitoria en torno a la aplicación de un elenco de procedimientos de carácter performativo que se desarrollan dentro de un horizonte estético determinado, y que son producidos de manera originaria dentro de una comunidad concreta pero desarrollados y consolidados a través de la influencia de otros estilos, prácticas o comunidades (Bastien, 1988).

Estas dos perspectivas apuntadas brevemente guardan relación directa con uno de los preceptos que conforman el sustrato natural de la teoría de los polisistemas: un sistema estratificado con un centro canonizado y una periferia no canonizada donde conviven un repertorio de modelos culturales de acuerdo a actividades primarias o de innovación, que se correspondería con el enfoque de la música jazz basado en procesos; y una serie de actividades secundarias o de conservación del elemento canonizado, que estaría más relacionada con la visión canónica del jazz como manifestación artística perteneciente a una comunidad cerrada y libre de influencias.

Ambas consideraciones son responsables o han influido de manera directa, en mayor o menor medida, en los procesos de globalización que han llevado la música jazz desde su origen, como expresión musical propia de un proceso sincrético de transculturización entre los exiliados africanos y la población nativa norteamericana, a constituirse en una música de carácter universal, que en su consideración de proceso creador, esencialmente, ha conseguido colonizar espacios de gran relevancia en el núcleo del sistema de la denominada música culta.

\section{DE LA PERIFERIA AL CENTRO DEL POLISISTEMA DE LA MÚSICA OCCIDENTAL}

La música jazz ha pasado en apenas un siglo de ser considerada como una música vulgar, popular, poco armoniosa, desordenada, nada academicista, y sociológicamente relacionada con los estratos sociales más deprimidos de América, a convertirse en un símbolo de elegancia, sofisticación, libertad expresiva, complejidad técnica e intelectual y armonía de vanguardia, pasando a ocupar un lugar privilegiado dentro del canon cultural de la música europea, y por extensión de la música occidental (Hendricks, 2014). Partimos de la base en este punto, de que, a lo largo de la historia, las formas y los géneros canonizados que han ostentado (y ostentan) un lugar central en el canon del polisistema musical son todos aquellos que de una manera u otra están relacionados con la denominada música clásica o música culta; o al menos los que cuentan con el auspicio o beneplácito de las 
JAVIER MERCHÁN SÁNCHEZ-JARA Y MARÍA NAVARRO CÁCERES

LA MÚSICA JAZZ EN LA INSTITUCIÓN EDUCATIVA: UN VIAJE DE TRASLACIÓN DE LA PERIFERIA

AL CORAZÓN DEL CANON DE LA MÚSICA CULTA EN OCCIDENTE

instituciones y agentes de influencia dentro de esta (Fink, 1998). La motivación de este fenómeno escapa, evidentemente, a las pretensiones y al alcance del presente trabajo, pero sirva a modo de pincelada la referencia a la propia definición de canon del profesor Even-Zohar, para ilustrar una consideración tan compleja. Si el propio Even-Zohar señala como indispensable la recepción y aceptación de las normas y las obras consideradas como legítimas por los poderes fácticos o dominantes dentro de la institución literaria (en nuestro caso institución musical), basta con hacer un recorrido histórico hasta el presente día para darse cuenta de que, en el ámbito musical, estos poderes dominantes (excluyendo la industria discográfica desarrollada en las últimas décadas) han estado y están representados, de manera casi exclusiva, por agentes pertenecientes a la esfera de la denominada música clásica. Desde las instituciones académicas (tanto a nivel interpretativo como teórico o de investigación); las instituciones políticas y/o administrativas; la esfera de la auctoritas en la crítica musical, hasta los centros e instituciones de recursos informativos han estado controlados o sometidos a los preceptos y los designios que emanan directamente del paradigma de la música clásica o música culta.

Por todo ello, la canonización de la música jazz ha supuesto mucho más que su propia consideración como música culta, su reconocimiento y respeto por parte de las administraciones y el establishment de La Institución, o la cesión de espacios preferentes en el escaparate de las compañías discográficas. Su inserción en el centro del polisistema de la música occidental ha supuesto y ha implicado, esencialmente, el reconocimiento de una canonicidad eminentemente dinámica capaz de investir cualquier género, forma o estilo con las características de su propio repertorio; $y$, lo que es más relevante, de fomentar per se la proliferación de nuevas formas y géneros como producto de la influencia directa de este. Este valor, de incalculable trascendencia en la evolución de la música del siglo XX, resulta aún más relevante y esencial al contraponerlo al otro gran centro canónico del polisistema de la música occidental, representado por la figura música clásica, toda vez que esta, al margen de su influencia (esencialmente a través de La Institución), representa una canonicidad esencialmente estática cuya influencia en el desarrollo de obras posteriores se limita básicamente (en el momento actual) a una pálida expresión a través de géneros como el de las bandas sonoras ${ }^{3}$ o la música para cine y el teatro musical (Wagnleitner, 2009).

3. La denominada música clásica contemporánea en muchos de los círculos que reniegan de las manifestaciones que preconizan el serialismo y paradigmas similares. 
JAVIER MERCHÁN SÁNCHEZ-JARA Y MARÍA NAVARRO CÁCERES

LA MÚSICA JAZZ EN LA INSTITUCIÓN EDUCATIVA: UN VIAJE DE TRASLACIÓN DE LA PERIFERIA

AL CORAZÓN DEL CANON DE LA MÚSICA CULTA EN OCCIDENTE

\section{LA INSTITUCIÓN (PROMOTORA) I. LAS UNIVERSIDADES}

Una de las circunstancias y acontecimientos históricos que sin lugar a dudas han resultado más determinantes para la promoción de la música jazz en el polisistema de la denominada música culta ha sido la creación y desarrollo de universidades y colleges con programas educativos específicos para este tipo de música, insertos dentro del sistema educativo de Estados Unidos, en primera instancia, y posteriormente en Reino Unido y el resto de Europa. No nos referimos, en este caso, al tipo de canonización, como ocurre en el ámbito literario, que se promulga (al margen de otros mecanismos y resortes) a través de las cátedras universitarias o de la producción científica que estas desarrollan y que cuentan además con el beneplácito y la confirmación de la crítica literaria (muchas veces inserta en las propias universidades). Nos estamos refiriendo en este caso a la institucionalización como paradigma musical, oficializado a través del desarrollo de titulaciones propias y específicas dentro del ámbito de la educación superior mediante programas de estudios convenientemente contrastados y evolucionados a los que acompañan sus propios espacios de investigación y producción de conocimiento académico.

Este hecho, junto con el altavoz mediático a nivel universal que supone la continua programación de este tipo de música al más alto nivel en centros culturales del prestigio del Carnegie Hall o el Lincoln Center, han sido los artífices de la puesta en marcha del proceso de institucionalización de la música jazz; primero en Estados Unidos y luego en el resto del mundo. Haciendo uso precisamente de una metáfora relacionada con el ámbito literario, las universidades de música moderna se han constituido como las propias editoriales del jazz y de otros estilos improvisados, mientras que los grandes centros culturales americanos primero, y europeos después, han otorgado a esta manifestación musical el necesario imprimatur que ha permitido la consolidación del género a nivel institucional. El gran trompetista y musicólogo norteamericano Wynton Marsalis hace referencia a esta cuestión de manera muy elocuente:

From our first downbeat as a summer concert series at Lincoln Center in 1987, to the fully orchestrated achievement of opening the world's first venue designed specifically for jazz in 2004, we have celebrated this music and these landmarks with an ever-growing audience of jazz fans from around the world.

Representing the totality of jazz music, Jazz at Lincoln Center's mission is carried out through four elements -educational, curatorial, archival, and ceremonial-capturing, in unparalleled scope, the full spectrum of the jazz experience. 
JAVIER MERCHÁN SÁNCHEZ-JARA Y MARÍA NAVARRO CÁCERES

LA MÚSICA JAZZ EN LA INSTITUCIÓN EDUCATIVA: UN VIAJE DE TRASLACIÓN DE LA PERIFERIA

AL CORAZÓN DEL CANON DE LA MÚSICA CULTA EN OCCIDENTE

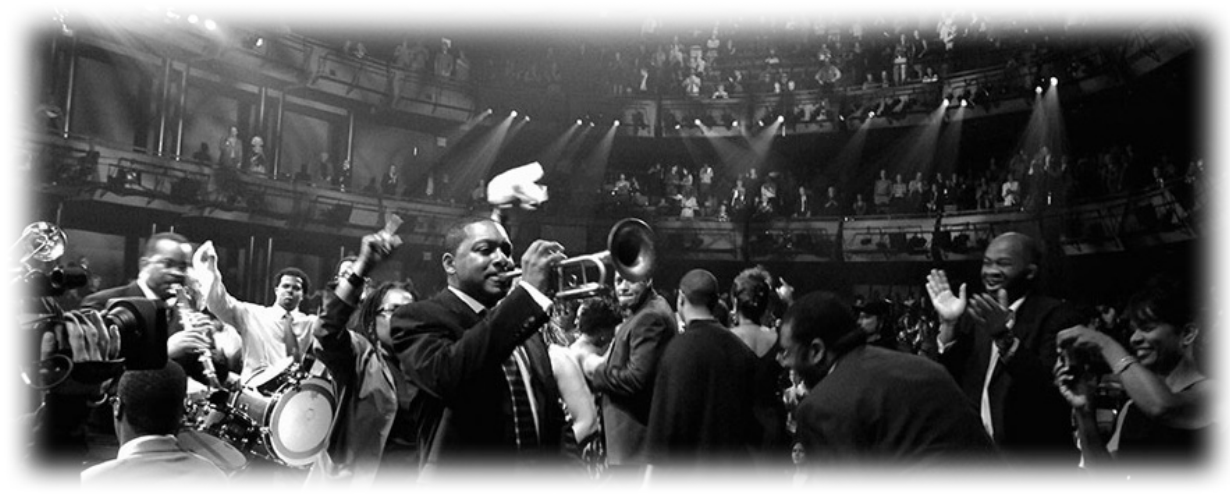

Ilustración 2. Jazz at Lincoln Center, referencia intelectual en la institución para la canonización del Jazz ${ }^{4}$.

In the mid-1980s, Lincoln Center, Inc. was looking to expand its programming efforts to attract new and younger audiences, and to fill its halls during the summer months when resident companies were performing elsewhere. Long-time jazz enthusiasts on the Lincoln Center campus and on the Lincoln Center Board recognized the need for America's music to be represented, and lobbied to include jazz in the organization's offerings. After four summers of successful Classical Jazz concerts, Jazz at Lincoln Center (JALC) became an official department of Lincoln Center in 1991. During its first year, JALC produced concerts throughout New York City, including Brooklyn and Harlem. By the second year, JALC had its own radio series on National Public Radio, and the Lincoln Center Jazz Orchestra (now known as the Jazz at Lincoln Center Orchestra) began touring, and recording and selling CDs. By its fourth year, the program reached international audiences with performances in Hong Kong and, the following year, in France, Austria, Italy, Turkey, Norway, Spain, England, Germany and Finland. In July 1996, JALC was inducted as the first new constituent of Lincoln Center since The School of American Ballet joined in 1987, laying the groundwork for the building of a performance facility designed specifically for the sound, function and feeling of jazz (Marsalis, 2016).

Este proceso ha resultado más relevante e interesante, si cabe, por incorporar, además, el interés sociológico de haber sido promovido en sus orígenes por actitudes de carácter proactivo relacionadas de manera exclusiva con el ámbito privado.

4. Fuente: In the Spirit of Swing; disponible: http://www.jazz.org/history consultado: 22/03/2016.

Ediciones Universidad de Salamanca / 
JAVIER MERCHÁN SÁNCHEZ-JARA Y MARÍA NAVARRO CÁCERES

LA MÚSICA JAZZ EN LA INSTITUCIÓN EDUCATIVA: UN VIAJE DE TRASLACIÓN DE LA PERIFERIA

AL CORAZÓN DEL CANON DE LA MÚSICA CULTA EN OCCIDENTE

La primera gran Universidad norteamericana en constituirse como clara impulsora de la música clásica norteamericana por excelencia es la Schillinger House, fundada en 1945 por Lawrence Berk, que posteriormente pasaría a conformarse bajo la denominación actual, en 1954, bajo la denominación de Berklee College of Music. La creación y puesta en marcha de esta universidad supuso una reacción en cadena cuya onda expansiva revolucionó el ecosistema de la enseñanza musical norteamericana, primero, y el del resto del mundo occidental después. Así, bajo el impulso y el auspicio de esta experiencia pionera se empiezan a crear otra serie de universidades y escuelas dedicadas a la música jazz, tanto de carácter privado, como dentro del ámbito público (en muchos casos a partir de las ya existentes), que adoptan o crean grados y másteres específicos para la enseñanza de este tipo de música. Si este hecho supone la consolidación de un elemento esencial en el ámbito de lo que Zhoar denomina La Institución ${ }^{5}$ específica, que ostenta el control en este sistema, la concreción de los currículos y de los programas educativos constituyen en cierta manera la formalización de un repertorio que permite sistematizar la creación del producto propio de este sistema. Además, las universidades producen, en el desarrollo de sus funciones y con cada generación de estudiantes, los agentes que trasmiten y diseminan este producto; no debemos de olvidar en este punto, por último, que la educación en base a una serie de preceptos y materiales consensuados y aceptados (Repertorio) es una de las herramientas más potentes de canonización.

Si en un primer lugar las instituciones como el Lincoln Center dieron acogida de forma natural a todos estos nuevos intérpretes y portadores del producto, que en definitiva representaban una nueva forma de música que se hacía cada vez más presente y relevante a través de la institución, en un segundo estadio estos mismos centros promovieron de forma proactiva, y ex profeso, la difusión de ciertas expresiones paradigmáticas del producto, con el fin último de posibilitar la formalización expresa del canon. En este sentido se puso en marcha la programación, estructurada y continuada, de conferencias, talleres, conciertos, seminarios, encuentros, etc., siendo la mayoría de estos eventos responsabilidad de muchos de los alumnos egresados de universidades como el Berklee College of Music.

5. Entendiendo el término institución como el conjunto de factores, poderes y recursos implicados en el mantenimiento del jazz, y de la música en general, como actividad sociocultural, convirtiéndose en el agente que rige las normas que prevalecen en esta actividad, sancionando unas y rechazando otras (Even-Zohar, 1990b). 
JAVIER MERCHÁN SÁNCHEZ-JARA Y MARÍA NAVARRO CÁCERES

LA MÚSICA JAZZ EN LA INSTITUCIÓN EDUCATIVA: UN VIAJE DE TRASLACIÓN DE LA PERIFERIA

AL CORAZÓN DEL CANON DE LA MÚSICA CULTA EN OCCIDENTE

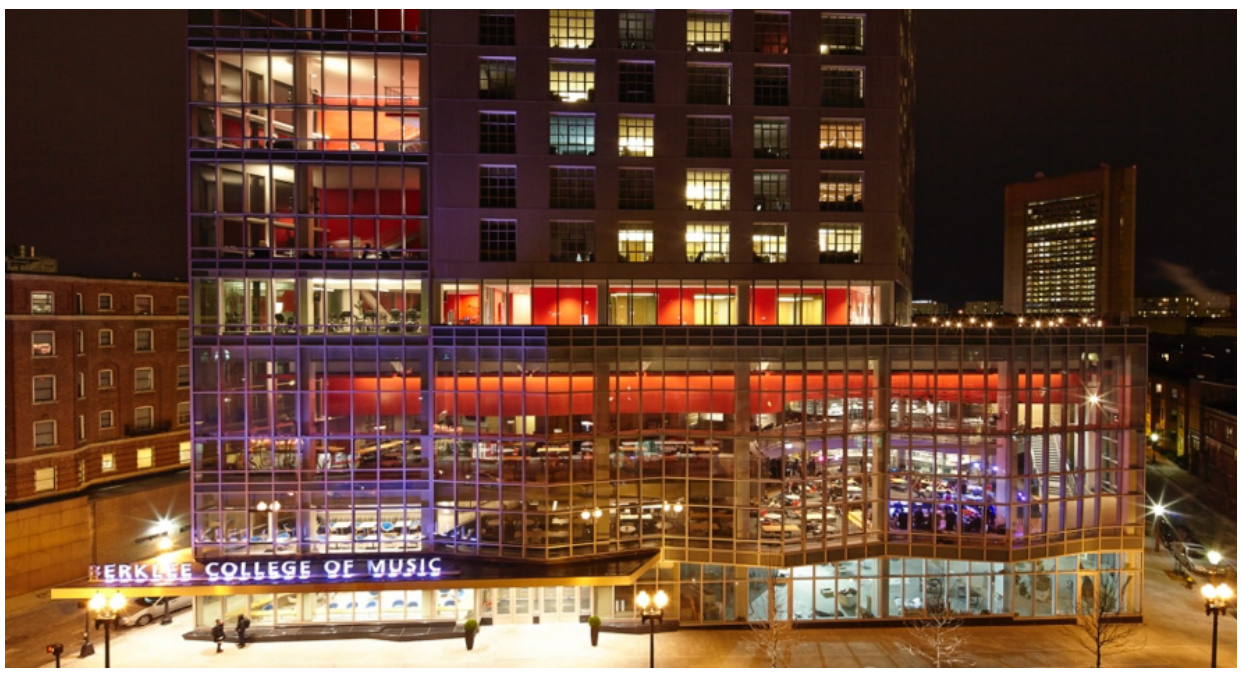

Ilustración 3. Berklee College of Music Residence Hall en Boston.

Pero, sobre todo, es de especial relevancia para la consolidación de la música jazz como género consolidado y autónomo dentro del sistema de la música la selección y compilación de las obras y autores que debían conformar el propio canon de la música jazz como materialización concreta de los rasgos y elementos definitorios de un nuevo sistema musical. Este se formalizaría oficialmente en el año 1973 en torno a la Smithsonian Collection of Classic Jazz, compilación realizada por Martin Williams (Thomas, 2002).

De forma subsidiaria, y muchas veces concurrente a estos acontecimientos de canonización de la música jazz en el polisistema musical americano, empezaron a surgir nuevas formas de expresión musical desarrolladas bajo la influencia directa de la anteriormente citada canonicidad dinámica presente en el género. Estas nuevas formas de carácter híbrido (jazz-fusion, jazz-rock, rock progresivo, etc.) fueron de igual manera insertándose en el sistema con la validación de las propias universidades, y en virtud de la necesidad de estas de ampliar los horizontes formativos a las demandas que de manera creciente iban surgiendo en la propia sociedad americana y en mucha de la europea que emigraba a Estados Unidos para poder estudiar en ellas.

En este punto es necesario subrayar que, si en un primer momento estas universidades se circunscriben casi de manera exclusiva al ámbito anglosajón e incorporan únicamente programas y currículos académicos centrados en la propia música jazz, la creciente demanda de alumnos potenciales, y el creciente interés por todas la nuevas formas creadas a la estela que el efecto de canonización del 
JAVIER MERCHÁN SÁNCHEZ-JARA Y MARÍA NAVARRO CÁCERES

LA MÚSICA JAZZ EN LA INSTITUCIÓN EDUCATIVA: UN VIAJE DE TRASLACIÓN DE LA PERIFERIA

AL CORAZÓN DEL CANON DE LA MÚSICA CULTA EN OCCIDENTE

jazz provoca en el resto de Europa (Reino Unido lo hizo tiempo antes), hace que surjan escuelas especializadas en este tipo de música; o que algunos de los conservatorios o universidades de carácter más aperturista comiencen a incorporar estas enseñanzas como parte de su programa de educativo. Este proceso colonizador del ámbito académico culmina de manera simbólica con la instalación en Valencia, en el año 2011, de la primera sucursal fuera de Estados Unidos de una de las universidades que dieron comienzo a todo este tipo de sinergias transformadoras: el Berklee College of Music.

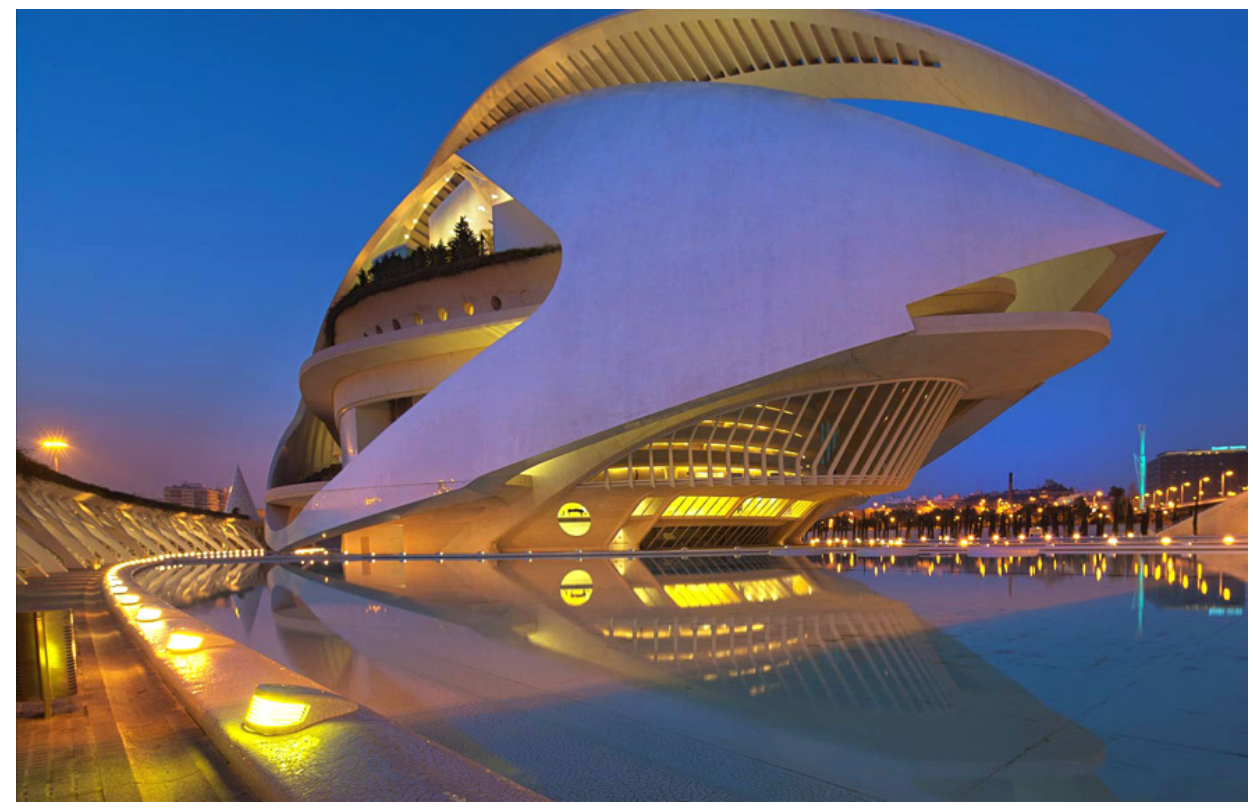

Ilustración 4. Palau de les Arts Reina Sofía, sede de la Berklee College of Music en Valencia.

Debemos hacer una reflexión explicita, en este sentido, en torno al hecho de cómo la fuerza disruptiva de la música jazz, potenciada por el efecto canonizador de su consideración de música culta a raíz del prestigio y la proyección alcanzados por la labor de difusión de las instituciones académicas en Norteamérica, ha propiciado que el conjunto de músicas de carácter improvisado (que en cierta forma forman parte del mismo sistema artístico o musical) haya sido susceptible de ser arrastrado o promovido, de igual forma, al centro del sistema.

Quizás el ejemplo más palpable, cercano e intuitivo, en este sentido, en el ámbito de la cultura española sea el de la música flamenca, expresión musical 
JAVIER MERCHÁN SÁNCHEZ-JARA Y MARÍA NAVARRO CÁCERES

LA MÚSICA JAZZ EN LA INSTITUCIÓN EDUCATIVA: UN VIAJE DE TRASLACIÓN DE LA PERIFERIA

AL CORAZÓN DEL CANON DE LA MÚSICA CULTA EN OCCIDENTE

que comparte con la música jazz muchas de las características constitutivas y propias de esta; por un lado, ambas son músicas de carácter transcultural, con un marcado carácter de discurso improvisado, y, por otro, ambas han transitado del ostracismo y la marginación que supone haber estado relegadas durante muchas décadas al ámbito más reducido de su producción, hasta convertirse en músicas universalmente aceptadas, apreciadas, consumidas y estudiadas.

Con la inserción de la música jazz en el centro del polisistema musical de Occidente no solo se canoniza un género o estilo en el sentido de conjunto de exigencias estéticas, técnicas e interpretativas o paradigmas armónicos, sino que de manera subsidiaria se canoniza, de igual manera, todo el conjunto de obras y temas paradigmáticos de este estilo; así los real books de jazz o blues, que en definitiva representan una suerte cancioneros de la música popular americana (Young y Matheson, 2000), se han consolidado como la compilación de las obras canónicas de este sistema musical.

No obstante, durante este periodo de inserción en el polisistema de la música culta occidental surgen, de igual manera, conflictos y tensiones intersistémicas. Uno de los problemas aparece con todo el grupo de nuevas formas surgidas por influencia del propio estilo definido como jazz canónico, toda vez que en muchos casos algunas expresiones alumbradas, por ejemplo, en la era post-bebop representan posturas irreconciliables con la propia tradición canonizada. Se configuran así dos grupos o corrientes de opinión que pugnan por ejercer el control dentro de la institución y que mantienen posturas antagónicas; por un lado, los neocanónicos, que postulan la preservación de la tradición y una evolución natural de esta, alejada de la influencia de los circuitos comerciales; y los que defienden las nuevas formas surgidas al amparo del término fusión (concepto paraguas que aglutina muchos de los estilos surgidos en torno a la segunda época creativa de Miles Davis), que defienden estas nuevas formas y géneros como la evolución lógica de una música plenamente viva que busca todos los cauces posibles para experimentar y desarrollarse (Magee, 2007).

Al final, estos desencuentros desembocan (al margen de las razones que cada postura propone en relación con los aspectos más representativos del jazz como forma canónica) en la pugna entre la propia institución del jazz, responsable del impulso al corazón del sistema, y las nuevas formas emergentes que aspiran a ser legitimadas como parte del corpus canonizado. Este hecho representa dentro del polisistema de la música jazz la misma pugna que históricamente se ha producido entre la institución musical con mayúsculas (el ecosistema de la música clásica) que sistemáticamente ha despreciado la mayoría de expresiones musicales relacionadas con la cultura pop o rock (que en muchos casos se desarrollan como influencia directa de esta) (Merchán Sánchez-Jara, 2014) y el resto de formas aspirantes a ocupar el centro (o un parte privilegiada) en el polisistema de la música occidental. 
JAVIER MERCHÁN SÁNCHEZ-JARA Y MARÍA NAVARRO CÁCERES

LA MÚSICA JAZZ EN LA INSTITUCIÓN EDUCATIVA: UN VIAJE DE TRASLACIÓN DE LA PERIFERIA

AL CORAZÓN DEL CANON DE LA MÚSICA CULTA EN OCCIDENTE

\section{LA INSTITUCIÓN (OPOSITORA) II. EL JAZZ EN EL ECOSISTEMA DE LA MÚSICA CLÁSICA}

Si existe un género musical que ha ostentado históricamente el centro del polisistema de la música y los resortes de su institución ha sido, y en cierta forma sigue siendo, el ecosistema de la conocida como música clásica o música culta. Su largo desarrollo histórico y cronológico, sociológico o cultural implica no solo una potentísima herramienta de legitimación de la consideración apuntada con anterioridad, sino que posibilita que hablemos de un auténtico sistema que reúne la mayor parte de los hitos, paradigmas y figuras destacadas en casi cualquier aspecto imaginable de la práctica musical en Occidente. Tanto es así que, desde los más remotos tiempos hasta nuestros días, en la mayor parte de los contextos en los que aparece el término música, invocado de manera genérica, lleva implícito en el subconsciente colectivo la cualidad o el referente a la música clásica; de tal forma que hablar de música a nivel de programas académicos, de recursos administrativos o de conocimiento científico implica necesariamente, y de manera implícita, hablar de música clásica. La pregunta en este punto es inevitable: ¿cuál, o qué, es la música clásica? Es este un aspecto central en el desarrollo del presente trabajo y de cualquier otro que verse sobre la pugna de fuerzas en el polisistema de la música. ¿Cuáles son los elementos y los rasgos comunes que permiten agrupar en un mismo concepto una práctica que engloba decenas de siglos de manifestaciones musicales? ${ }^{6}$. ¿Por qué se consideran música clásica las expresiones musicales de carácter popular que surgen en la Edad Media y no sucede lo mismo con todas aquellas que acontecen en el acervo de la cultura popular del siglo XX?

Evidentemente, las implicaciones subyacentes al factor histórico o cronológico pueden ser una primera respuesta a este tipo de legitimación selectiva, toda vez que el paso del tiempo incorpora per se, en muchas ocasiones, un efecto canonizador sobre ciertas formas o géneros que en definitiva se demuestran como fundacionales de un género, o influyentes sobre el mismo, en un grado extraordinario; en cualquier caso, este elemento resulta insuficiente, cuando menos, para dar una explicación científicamente valida y de carácter holístico a la cuestión planteada. Abundando en la cuestión, esta respuesta sería extremadamente superficial para la magnitud y la complejidad del problema. De igual manera, la apelación de manera indistinta a la música culta (y a esta cualidad como hecho diferenciador) como referente que sustituye al concepto de música clásica, además de constituirse en un concepto políticamente incorrecto que puede resultar hasta ofensivo en una

6. Evidentemente nos referimos en este punto al concepto música clásica como género global, y no de manera específica al denominado periodo clásico o clasicismo representado de manera icónica en las figuras de Mozart y Haydn. 
JAVIER MERCHÁN SÁNCHEZ-JARA Y MARÍA NAVARRO CÁCERES

LA MÚSICA JAZZ EN LA INSTITUCIÓN EDUCATIVA: UN VIAJE DE TRASLACIÓN DE LA PERIFERIA

AL CORAZÓN DEL CANON DE LA MÚSICA CULTA EN OCCIDENTE

sociedad tan plural como la actual, queda igualmente deslegitimizado por las mismas razones que en el caso anterior.

Otro de los aspectos que con más frecuencia se aluden para investir a un cierto género o forma musical como imprescindible para ingresar en el corpus de la denominada música clásica es el carácter academicista que de manera inmanente gran parte de su producción incorpora. Nos referimos, en este sentido, a su condición de música producida bajo los preceptos y los agentes insertos en las instituciones de enseñanza musical reconocidos por la institución, y bajo métodos de enseñanza y formas de producción determinados. Esta reflexión incorpora ciertos aspectos cuestionables; si bien es cierto que la figura de la academia es consustancial a la de la institución promotora del canon, no es menos cierto que son, y han sido, muchos los hitos dentro de la música clásica (casi siempre los más revolucionarios, subversivos, y que más han contribuido a expandir sus fronteras) los que apuntan a agentes, géneros y formas dentro del canon desarrollados al margen de la academia. Uno de los ejemplos más ilustrativos lo encontramos, por ejemplo, en la figura de Richard Wagner, músico eminentemente autodidacta ${ }^{7}$ y que revoluciona la música del siglo XIX precisamente con postulados que rompían los preceptos armónicos y estructurales más asentados en la academia y en el repertorio de la época (Blasius, 2001).

Una reflexión más perspicaz, quizás, en este sentido, afirma que, independientemente del obligado paso por la academia, la música clásica debe incorporar el interés artístico suficiente como para merecer la atención de la comunidad académica para incorporarla a los centros de enseñanza. Es precisamente Wynston Marsalis, uno de los promotores de la creación del canon del jazz, quien se apropia y esgrime esta consideración, promulgada históricamente en el ámbito de la música clásica, como rasgo diferenciador de lo que él, y la institución que representa, consideran las características del jazz canónico frente a las músicas de fusión; en su opinión, más cercanas a la música pop:

What makes fusion not jazz is that certain key elements of jazz are not addressed. First and foremost the blues. If you aren't addressing the blues you can't be playing jazz. Then the second thing is that music, in its 20-something years of existence, has become just what it always wanted to be-pop music ... [F]usion ... relieves us, our country, of the problem of dealing with jazz and the contribution of the Negro to the mythology of America. The question in jazz has always been: is it pop music or is it a classical music? And I don't mean classical in terms of European music, but I mean does it have formal aspects that make it worthy of study,

7. Aunque recibió una cortísima formación musical de apenas unos meses, Wagner desarrolla la parte más relevante de creación al margen de la academia y de los cánones armónico-teóricos imperantes en la época. 
JAVIER MERCHÁN SÁNCHEZ-JARA Y MARÍA NAVARRO CÁCERES

LA MÚSICA JAZZ EN LA INSTITUCIÓN EDUCATIVA: UN VIAJE DE TRASLACIÓN DE LA PERIFERIA

AL CORAZÓN DEL CANON DE LA MÚSICA CULTA EN OCCIDENTE

and does it carry pertinent mythic information about being American ... [T] musicians ... relieved all of the cultural pressure that Duke Ellington placed on our nation to address the music seriously and teach it, which would make us deal with ourselves and our racism, which everyone knows is our greatest problem, even more so than dope ${ }^{8}$.

Otro de los argumentos, quizás entre los más ingenuos, que históricamente se han manejado como base para la distinción entre música clásica y música popular es el medio de producción; tanto a nivel vocal como, sobre todo, instrumental. La apelación al uso de instrumentos acústicos como los distintivos de la música clásica frente a instrumentos eléctricos o electrónicos (estos últimos reconocidos y utilizados en los estilo de la música clásica de vanguardia), como los relacionados con la música moderna, cae por su propio peso toda vez que la música jazz, por ejemplo, presenta como su formación más prototípica los cuartetos o quintetos formados en exclusividad por instrumentos acústicos; de esta manera no podemos considerar este tipo de formaciones y medio de producción como formas privativas de la música clásica. De igual manera dentro de la música electro-acústica producida en las últimas décadas abunda el uso y utilización de instrumentos con base eléctrica o electro-acústica, sin que este hecho implique su pérdida de consideración como expresión propia de lo que se conoce como música clásica.

Quizás dentro de la reflexión anteriormente aportada en la declaración de Marsalis, aun sin ser expuesta de manera intencionada con este propósito, podemos encontrar una de las motivaciones más convincentes para la caracterización y definición de los límites o elementos que conforman tanto el paradigma de la música clásica como del género jazz. En este sentido una interpretación o lectura de la expresión música clásica (en referencia al jazz), como a la que alude Marsalis en el anterior fragmento, en clave de música producida según el repertorio (en la acepción propuesta por Evn-Zohar) clásico o canónico, nos permite fijar algunos de los elementos que son indiscutibles, desde cualquier prisma, para la categorización de la música clásica y, también (aunque en menor medida), de la música jazz. Marsalis intenta expresar (quizás de la manera menos precisa) que el jazz y la tradición que él representa considera canónico aquello que conforma el conjunto de productos realizados en torno a un repertorio establecido en función de una serie de rasgos concretos. De manera análoga la música clásica (en su concepción más generalizada), esta vez sí, puede definirse en sus aspectos más caracterizadores en torno al siguiente conjunto de elementos: un conjunto de formas musicales claramente definidas y consolidadas en el tiempo; un paradigma melódico-armónico propio de cada época, género o estilo que es identificable y reconocible; un medio de

8. Fuente: Thomas, Gregory V. (2002). The Canonization of Afro-American Literature. Callaloo, 25.1, 280-308. 
JAVIER MERCHÁN SÁNCHEZ-JARA Y MARÍA NAVARRO CÁCERES

LA MÚSICA JAZZ EN LA INSTITUCIÓN EDUCATIVA: UN VIAJE DE TRASLACIÓN DE LA PERIFERIA

AL CORAZÓN DEL CANON DE LA MÚSICA CULTA EN OCCIDENTE

producción esencialmente basado en instrumentos acústicos o electro-acústicos (no eléctricos, electrónicos o sintetizados); y una forma de trasmisión basada en la interpretación de obras previamente escritas donde generalmente la figura del creador está claramente diferenciada de la del intérprete, incluso cuando un mismo agente adopte de manera indistinta ambos roles.

De igual manera, en el género jazz Marsalis y otros agentes de la institución establecen una serie de elementos como los esencialmente constitutivos del jazz conocido como tradición: influencia directa y omnipresente de las estructuras formales y armónico-melódicas de la forma blues; paradigma rítmico basado en conceptos como el desplazamiento, el swing y el laid-back; y quizás el más importante, la producción artística basada en la conversación espontánea ${ }^{9}$ y sincrónica entre intérpretes. Es precisamente a través del intercambio de muchos de estos aspectos definitorios de ambos paradigmas de donde emanan muchas las nuevas formas híbridas entre los dos sistemas, que van a ser un elemento esencial en la legitimación de la música jazz por parte de la institución clásica.

Esta interacción entre géneros o paradigmas se ha producido a lo largo del tiempo, en primer lugar, como la consecuencia inevitable cuando dos sistemas entran en contacto. En estos contextos, estos sistemas utilizan elementos del repertorio ajeno como herramienta para expandir y potenciar las posibilidades expresivas o creativas de uno u otro sistema. En segundo lugar, como elemento o vehículo de traslación entre estratos dentro de las jerarquías establecidas en los propios sistemas. Podemos constatar como, en muchas ocasiones, la fusión de estilos populares con la música clásica (el más prototípico y desarrollado es de la música Heavy Metal), al margen de constituirse como una nueva forma de expresión para ampliar los horizontes estéticos y creativos de esta, ha introducido de manera notoria, además, un efecto legitimador o prestigiador de una música que en sus comienzos representaba una de las formas más denostadas o infravaloradas de la denominada música popular.

En el caso de la interacción entre la música jazz y la música clásica, esta ha producido, a la postre, un impacto mucho más intenso y radical en relación con la consideración sociocultural de una música como el jazz que comenzó siendo un género musical de carácter eminentemente minoritario y marginal, al menos fuera de su circunscripción geográfica originaria. Este impacto ha alcanzado cotas tan altas de influencia que el explícito interés de muchos de los autores canónicos de la música clásica en la segunda mitad del siglo XX ha integrado algunos de los rasgos identificativos de este género musical con el resultado de la generación de

9. El término espontánea hace alusión a la creación no predeterminada del material rítmico-melódico presente en las improvisaciones, lo cual no implica de la existencia previa de un marco normativo para su desarrollo, basado en la propia estructura del tema que se interpreta. 
JAVIER MERCHÁN SÁNCHEZ-JARA Y MARÍA NAVARRO CÁCERES

nuevas formas híbridas entre ambas culturas, y, lo que es más importante para la cuestión que analizamos, la apertura de la institución a la llegada del jazz al centro del sistema de la música occidental.

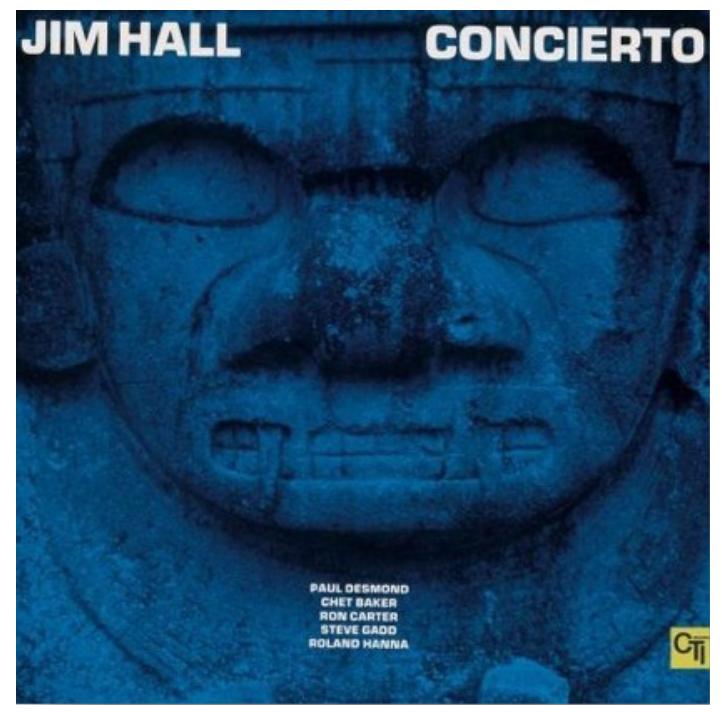

Ilustración 5. Versión del Concierto de Aranjuez en clave jazz.

Un ejemplo paradigmático lo encontramos en la figura de Igor Stravinski, compositor clásico, academicista y prototípico del canon de la música clásica occidental del siglo XX. Su interés por la música jazz surge, al margen de otras cuestiones, como necesidad de renovar una cultura musical como la europea en franca decadencia ${ }^{10}$, desde la pureza de las nuevas fuerzas expresivas de origen y esencia primitiva (Mellers, 1967). La relación de Stravinski con el jazz ha producido no solo las primeras obras con hibridación formal de elementos esenciales de ambas culturas, sino uno de los grandes hitos para el reconocimiento del jazz por parte de la institución de la música clásica en Europa.

10. Como el propio Even-Zohar postula, los movimientos más relevantes en los polisistemas surgen en periodos de crisis y convulsión, propiciando que muchas formas sean trasladadas del centro a la periferia o viceversa y otras ocupen el vacío que estas dejan.

Ediciones Universidad de Salamanca /

(요 PopularMusicResearchToday,2,2(2020),pp.5-31 


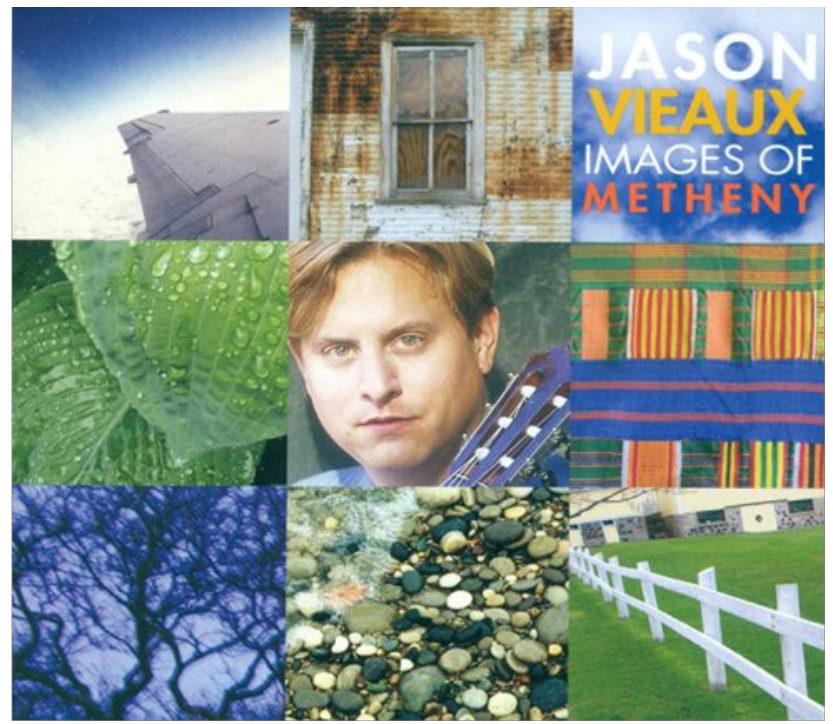

Ilustración 6. Images of Metheny; lectura de la obra de Metheny en guitarra clásica.

A partir de este momento se sucede de forma continuada la proliferación exponencial de manifestaciones artísticas que fusionan elementos esenciales de ambas culturas. Si en un primer momento esta producción surge de manera unidireccional desde el ámbito de la música clásica hacia el ámbito jazz, en etapas posteriores este flujo de intercambios se desarrolla de manera bidireccional con el surgimiento de obras desde el ámbito del jazz canónico, y a través la incorporación de estructuras y elementos propios de la música clásica.

Desde entonces estas hibridaciones se han producido en casi cualquier ámbito imaginable; desde la reinterpretación de temas jazz adaptados al ámbito clásico como la última grabación del guitarrista canadiense Jason Vieaux, sobre la obra de Pat Metheny, hasta los ejemplos de confluencia de repertorios más extremos como la obra Officium, donde Jan Garbarek (saxofonista formado en el estilo jazz) improvisa según los recursos estéticos de la tradición jazz sobre una base armónica constituida por obras pertenecientes al ámbito de la polifonía medieval y renacentista. Es este un ejemplo que reúne y sintetiza muchas de las consideraciones expuestas en este trabajo. Por un lado, la producción se ha erigido como uno de los hitos que marcan la inserción plena de la música jazz en el corazón del polisistema, además de revelarse como un éxito comercial sin precedentes, convirtiéndose en uno de los discos de música clásica más vendidos de la década. Este hecho supuso, de manera concurrente, el espaldarazo definitivo para el sello 
JAVIER MERCHÁN SÁNCHEZ-JARA Y MARÍA NAVARRO CÁCERES

LA MÚSICA JAZZ EN LA INSTITUCIÓN EDUCATIVA: UN VIAJE DE TRASLACIÓN DE LA PERIFERIA

AL CORAZÓN DEL CANON DE LA MÚSICA CULTA EN OCCIDENTE

discográfico que produce la obra y que desde entonces ha orientado su desempeño, de manera especializada, a este tipo de hibridaciones entre géneros. Muchas de sus producciones se han convertido en obras aceptadas y avaladas de manera unánime y sin ambages por una inmensa mayoría de la crítica más tradicional en el contexto de la música clásica.

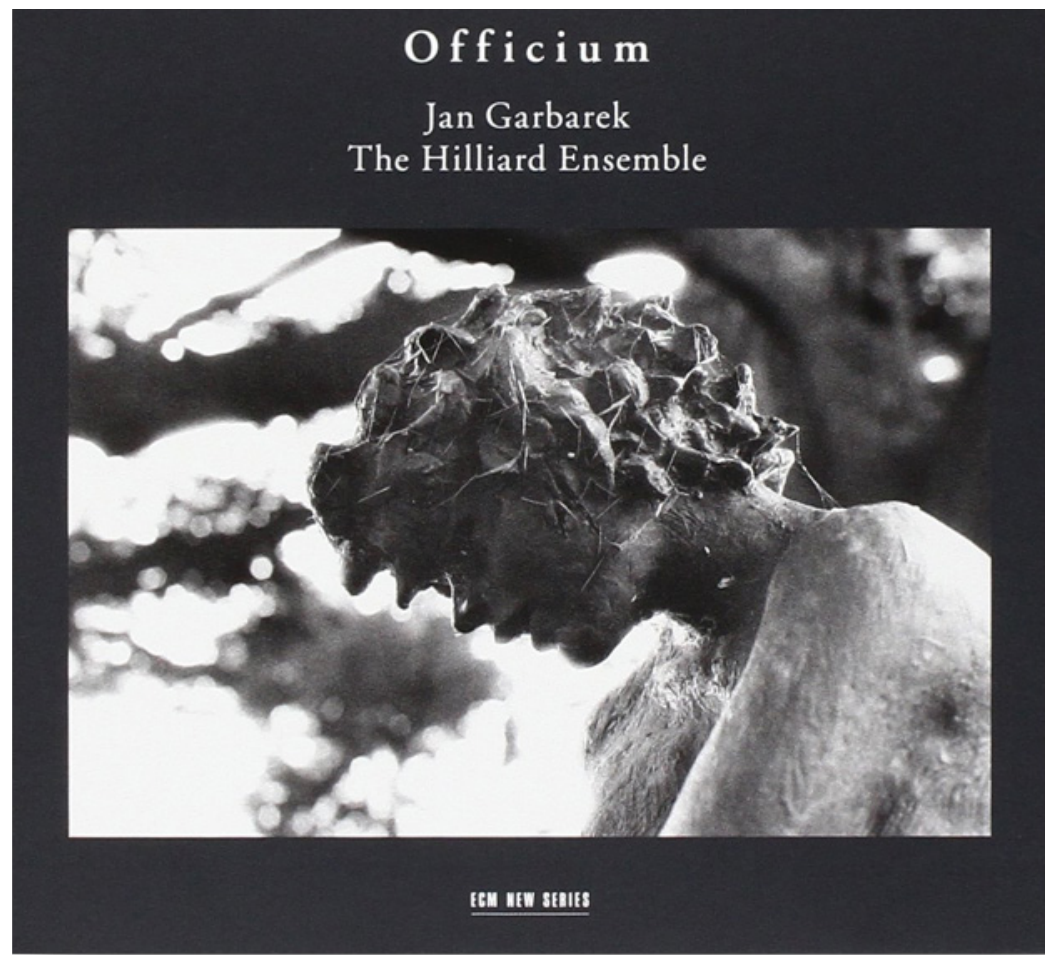

Ilustración 7. Officium, hibridación de polifonía renacentista con jazz.

\section{LA INSTITUCIÓN III. INDUSTRIA DISCOGRÁFICA Y CRÍTICA MUSICAL}

Entendiendo el concepto institución, según las teorías del propio Zohar, desde la perspectiva de los poderes dominantes y de influencia fáctica a nivel socioeconómico y cultural, se hace indispensable hacer referencia explícita a la industria discográfica para observar la evolución de cualquier estilo musical en nuestra época; con más intensidad, si cabe, en relación con la música surgida a partir del siglo XX. Si restringimos el concepto de influencia al campo económico, no es difícil 
JAVIER MERCHÁN SÁNCHEZ-JARA Y MARÍA NAVARRO CÁCERES

LA MÚSICA JAZZ EN LA INSTITUCIÓN EDUCATIVA: UN VIAJE DE TRASLACIÓN DE LA PERIFERIA

AL CORAZÓN DEL CANON DE LA MÚSICA CULTA EN OCCIDENTE

acordar que ninguna industria como la discográfica ha ostentado tanto poder, y por lo tanto ascendencia, desde cualquier punto de vista posible.

La lógica búsqueda incesante del rendimiento económico ha hecho que esta influencia se traduzca, sobre todo en los estilos menos comerciales como el jazz, en procesos y fuerzas sinérgicas que se movilizan para acercar este tipo de estilos a corrientes, vanguardias e hibridaciones que supongan una mejora en la perspectiva económica, dentro del desarrollo del propio género. Estas tendencias y movimientos discurren generalmente de manera solapada a la propia evolución y desarrollo de formas y estilos; así, por ejemplo, observamos como el jazz, visto desde la perspectiva más innovadora de género musical considerado como proceso, deriva de manera sistemática hacia la asimilación e hibridación dentro de sistemas más comerciales; mientras que la corriente canónica se revela como la fuerza opositora que intenta preservar la tradición en su forma primigenia y aislada de contaminaciones y de influencias de otros estilos o géneros; con más fuerza aún cuando detrás de esta contaminación subyacen intereses económicos.

En cualquier caso, la industria discográfica como componente esencial de la institución ha jugado un papel indiscutible a favor del impulso de la música jazz hacia el centro del polisistema musical, y lo hace precisamente desde la perspectiva de la consideración de jazz como proceso creativo y de las características (anteriormente expuestas) que de forma inconsciente más se asocian a este estilo: vanguardia, estilo, libertad, improvisación, elitismo, esnobismo, etc.

Es a través de esta industria, y desde muchos de los productores que la representan, desde donde más se ha hecho por dar conocer al público en general este tipo de manifestaciones artísticas, además de provocar intencionadamente que el paradigma estético que lo representa se instale en la mayoría de los estilos; desde el pop a la música clásica. Si su inserción en el contexto de la música pop ha supuesto su globalización en los circuitos comerciales y de difusión ${ }^{11}$, la relación con el segundo (la música clásica) ha supuesto, como ya hemos comentado, la obtención del salvoconducto que ha permitido su incursión hacia el centro del polisistema.

Quizás el ejemplo más prototípico de esta suerte de transformaciones que se producen dentro del contacto entre la música jazz y la música clásica en relación al encumbramiento conjunto de crítica y éxito comercial podamos observarlo en la obra de Keith Jarret, y más concretamente su grabación del Concierto de Köln, el álbum de piano más vendido de la historia y una de las obras cumbres del jazz moderno y de fusión, donde la influencia clásica no solo aparece a nivel de fraseo, melodía, armonía, sino en la propia esencia performativa. El género de piano a

11. Un ejemplo muy notorio es el álbum multiplatino de Sting Nothing like the sun, trufado de recursos y guiños a la música jazz gracias a la intervención de su productor Bryan Loren. 
JAVIER MERCHÁN SÁNCHEZ-JARA Y MARÍA NAVARRO CÁCERES

LA MÚSICA JAZZ EN LA INSTITUCIÓN EDUCATIVA: UN VIAJE DE TRASLACIÓN DE LA PERIFERIA

AL CORAZÓN DEL CANON DE LA MÚSICA CULTA EN OCCIDENTE

solo, hasta el momento casi exclusivo de la música clásica, y el tipo o formato de concierto en una sala con el ritual y el ceremonial propio de los conciertos clásicos convierten este acontecimiento en la chispa que ha propiciado que muchas de las barreras que el canon clásico custodiaba celosamente hayan caído y otras muchas estén en vías de desaparecer. En este sentido la canonización de la música jazz ha implicado cambios substanciales en la música clásica; desde la apertura del repertorio a formas de hibridación entre géneros o formaciones instrumentales, hasta la propia puesta en escena, la actitud, etc. Este álbum, y algunos más de características similares que en el fondo representan nuevas formas o subgéneros dentro del polisistema musical, han actuado como avanzadilla de la propia música jazz hasta el centro del sistema; y, lo que es más relevante, para la posterior modificación de prácticas en la institución. Ejemplos como el de Köln representan cuánto de rentable en el aspecto económico y comercial pueden llegar a ser estas nuevas formas surgidas al amparo de la hibridación con el jazz.

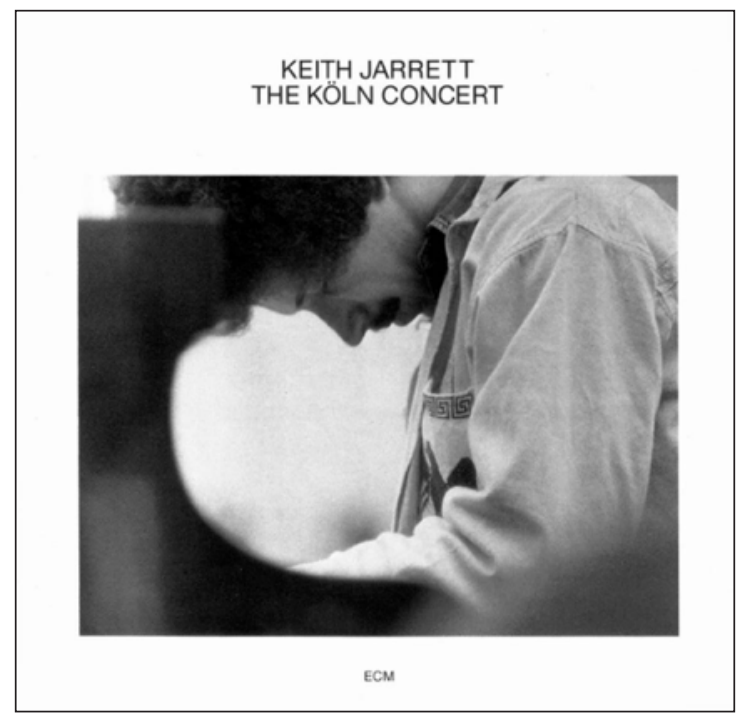

Ilustración 8. Portada de la obra de Keith Jarret The Köln Concert.

Todas estas cuestiones y acontecimientos han posibilitado que, en definitiva, la crítica especializada, sobre todo la proveniente de la esfera de la música clásica, haya efectuado un giro significativo para posicionarse a favor de esta manifestación musical, aprovechando el halo de intelectualidad, esnobismo e incluso elitismo que se ha ido generado en torno a ella. En este sentido podemos constatar que han proliferado, de manera muy acusada, blogs especializados en crítica musical 
JAVIER MERCHÁN SÁNCHEZ-JARA Y MARÍA NAVARRO CÁCERES

LA MÚSICA JAZZ EN LA INSTITUCIÓN EDUCATIVA: UN VIAJE DE TRASLACIÓN DE LA PERIFERIA

AL CORAZÓN DEL CANON DE LA MÚSICA CULTA EN OCCIDENTE

orientados al jazz o publicaciones de carácter divulgativo cuyos productores guardan relación con el ámbito de la música clásica, así como infinidad de estudios de carácter científico. Este movimiento de la crítica es un hecho constatado cargado de significación, hasta tal punto que podemos observar como, por ejemplo, las revistas más prestigiosas, elitistas, e incluso más ortodoxas, de la esfera de la música clásica, como Scherzo ${ }^{12}$, incorporan ya en forma de sección habitual espacios para la crítica de álbumes, conciertos o eventos de música jazz, cuando es impensable que en una publicación como esta tengan cabida, ni siquiera como mera referencia coyuntural, contenidos o alusiones referentes a géneros o estilos coetáneos al jazz como la música rock, pop, etc.

Esta recepción tan positiva por parte de la crítica, que como hemos subrayado constituye una parte esencial de la institución, ha investido a la música jazz de un poder legitimador similar al que ha tenido (y tiene) la música clásica. Según parte de la institución más beligerante en la defensa del canon clásico este es el hecho responsable de que muchas de las nuevas formas surgidas a través del contacto con otros sistemas empleen el término jazz de manera identificativa, como herramienta para conferir prestigio y respetabilidad, cuando, en la mayor parte de las ocasiones, nada o muy poco tienen que ver con este tipo de música. Se argumenta, además, no sin razón, que el único fin verdadero detrás del uso de este significante es la promoción y la mercantilización (Porter, 2002).

12. Desde su fundación en 1985, Scherzo ha querido ser una revista de información y de investigación musical. Cada uno de sus once números anuales incluye críticas de conciertos y de representaciones líricas, de discos y de libros, opiniones, perfiles de intérpretes y compositores, secciones de jazz y educación, así como un dosier mensual dedicado a un tema de especial relevancia, todo ello tratado desde el rigor técnico y a través de un estilo que cubra las expectativas tanto de los expertos como del público no especializado. Scherzo está presente en España y en el extranjero con corresponsales y suscriptores en los principales centros musicales. La revista, además, forma parte del jurado -como único miembro español- de los International Classical Music Awards. Scherzo está disponible tanto en papel como en edición digital.

Fuente: revistasculturales.com disponible en: < http://www.revistasculturales.com/revistas/60/scherzo/> consultado [12/01/2016]. 


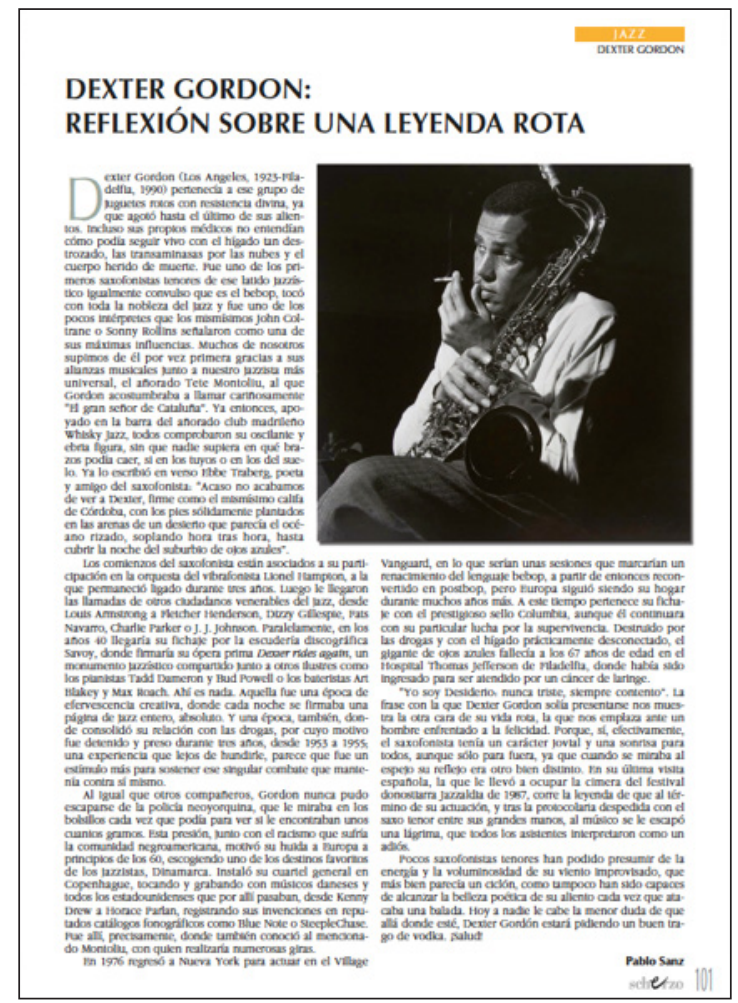

Ilustración 9. Sección permanente dedicada a la música jazz en la revista Scherzo.

Ante todo este tipo de pugnas dentro del sistema, a las que se suma la controversia surgida en torno a la corriente denominada free jazz ${ }^{13}$, y la amenaza de desnaturalización del género, percibida por muchos de los miembros de la institución, se han creado corrientes unificadoras dentro de la crítica con el fin de materializar la reformulación de una antología con carácter constituyente que represente el canon americano de la música jazz o lo que es lo mismo, como muchas voces afirman, el canon de la música clásica americana. Estos esfuerzos de canonización cristalizan en 2011 con la publicación de la obra Jazz: The Smithsonian Antology ${ }^{14}$. Este compendio editado por el Instituto Smithsonian de Washington

13. Esta corriente tiene su paralelismo dentro de la música clásica, salvando las distancias, en el movimiento conocido como serialismo.

14. Jazz: The Smithsonian Anthology. Editado por Smithsonian Folkways Recordings (Karonte).

Ediciones Universidad de Salamanca / 
JAVIER MERCHÁN SÁNCHEZ-JARA Y MARÍA NAVARRO CÁCERES

LA MÚSICA JAZZ EN LA INSTITUCIÓN EDUCATIVA: UN VIAJE DE TRASLACIÓN DE LA PERIFERIA

AL CORAZÓN DEL CANON DE LA MÚSICA CULTA EN OCCIDENTE

como actualización de la obra de Williams esconde, detrás de la propia pretensión de aunar criterios formales que representan la esencia de la música jazz, reivindicar su esencia american $a^{15}$ en una época en la que se empieza a debatir la existencia de una corriente europea que amenaza con configurar un polisistema musical de carácter bicéfalo dentro de la música jazz. Es de esperar que esta corriente intrasistémica encuentre fuerzas opositoras de relevancia, toda vez que, aun fuera del canon tradicional, gran parte de los exponentes más significativos de la música jazz siguen perteneciendo al ámbito norteamericano (Levine, 1989) (o al menos anglosajón), la realidad permite hablar de un polisistema de carácter bicéfalo dentro de la música occidental; un gran sistema donde conviven y se relacionan el sistema de la denominada música moderna, en cuyo centro ocupa un lugar preferente la música jazz, y otro gran sistema cuyo corazón está ocupado por la música clásica europea.

\section{BIBLIOGRAFÍA}

Bastien, D. T. y Todd, J. H. (1988). Jazz as a process of organizational innovation. Communication Research, 15(5), 582-602.

Blasius, L. D. (2001). Nietzsche, Riemann, Wagner: when music lies. En S. Clark y A. Rehding (Eds.), Music Theory and Natural Order from the Renaissance to the Early Twentieth Century (pp. 93-107). Cambridge: Cambridge University Press.

Citron, M. (2000). Gender and the musical canon. Cambridge [England]; New York: Cambridge University Press.

Even-Zohar, I. (1979). Polysystem Theory. Politics Today: International Journal for Theory and Analysis of Literature and Communication, 1(1-2).

Even-Zohar, I. (1990a). Polysystem Studies. Poetics Today: International Journal for Theory and Analysis of Literature and Communication, 11(1).

Even-Zohar, I. (1990b). The Literary System. Poetics Today, 11(1), 27-44.

Fink, R. (1998). Elvis everywhere: Musicology and popular music studies at the twilight of the canon. American Music, 16(2), 135-179.

Gunderson, F. (2003). The African Diaspora: A Musical Perspective. New York, NY, USA: Routledge. Critical and Cultural Musicology, 3.

Hendricks, K. S. (2014). Changes in self-efficacy beliefs over time: Contextual influences of gender, rank-based placement, and social support in a competitive orchestra environment. Psychology of Music, 42(3), 347-365.

Levine, L. (1989). Jazz and American Culture. American Foklore Society, 102(4), 6-22.

Magee, J. (2007). Kinds of Blue: Miles Davis, Afro-Modernism, and the Blues. Journal Jazz Perspectives, 1(1), 5-27.

15. El propio Even-Zohar subraya la cualidad del repertorio como herramienta para conformar o confirmar identidades colectivas. 
JAVIER MERCHÁN SÁNCHEZ-JARA Y MARÍA NAVARRO CÁCERES

LA MÚSICA JAZZ EN LA INSTITUCIÓN EDUCATIVA: UN VIAJE DE TRASLACIÓN DE LA PERIFERIA

AL CORAZÓN DEL CANON DE LA MÚSICA CULTA EN OCCIDENTE

Marsalis, W. (2016). Jazz at the Lincoln center [en línea]. S. 1.: jazz.org. Disponible en: http://www.jazz.org/history/. [Access: 22 de agosto de 2016].

Mellers, W. (1967). Stravinsky and Jazz. Tempo; Cambridge University Press, 81(1), 29-31.

Merchán Sánchez-Jara, J. F. (2014). Digital schola: music readers as learning/teaching tools. En ACM (Ed.), Proceedings of the Second International Conference on Technological Ecosystems for Enhancing Multiculturality, 1(1), 547-553.

Monson, I. (1995). The problem with white hipness: Race, gender, and cultural conceptions in jazz historical discourse. Journal of the American Musicological Society, 48(3), 396-422.

Porter, E. (2002). What Is This Thing Called Jazz?: African American Musicians as Artists, Critics and Activists (Music of the African Diaspora). Los Angeles: University of California Press.

Stempel, L. (2010). Showtime: a history of the Broadway musical theater. New York: WW Norton.

Thomas, G. (2002). The canonization of Afro-American literature. Callaloo, 25(1), 288-308.

Wagnleitner, R. (2009). Jazz, the Classical Music of Globalization en Satchmo Meets Amadeus. Wien: Trasatlantica.

Young, J. y Matheson, C. (2000). The Metaphysics of Jazz. The Journal of Aesthetics and Art Criticism, 58(2), 125-133.

\section{Grabaciones discográficas}

Various Artists (2011). Jazz: The Smithsonian Anthology. CD. Washington, D.C.: jazz, blues, ragtime.

Hall, J.; Desmond, P.; Baker, C. y Carter, R. (1975). Concierto. CD. Englewood Cliffs: Van Gelder Studio, Jazz.

Jarret, K. (1975). The Köln Concert. CD. Opera House, Cologne: Jazz. ECM.

The Hilliard Ensemble y Garbarek, J. (1994). Officium. CD. Propstei St. Gerold, Austria: Jazz, classical. ECM.

Ediciones Universidad de Salamanca / ㅛ PopularMusicResearchToday,2,2(2020),pp.5-31 
